06,05

\title{
Магнитные и электрические свойства кристаллических материалов на основе халькогенидов индия и меди в широкой области температур и давлений
}

\author{
(C) Н.В. Мельникова ${ }^{1}$, Ю.А. Кандрина ${ }^{1}$, А.В. Тебеньков ${ }^{1}$, Е.А. Степанова ${ }^{1}$, \\ А.Н. Бабушкин ${ }^{1}$, А.Ю. Моллаев ${ }^{2}$, Л.А. Сайпулаева ${ }^{2}$, А.Г. Алибеков ${ }^{2}$ \\ 1 Уральский федеральный университет, Институт естественных наук, \\ Екатеринбург, Россия \\ ${ }^{2}$ Институт фризики им. Х.И. Амирханова ДагНЦ РАН, \\ Махачкала, Россия \\ E-mail: nvm.melnikova@gmail.com
}

(Поступила в Редакцию 14 июня 2016 г.)

Проанализировано влияние температур $(2-300 \mathrm{~K})$ и высоких давлений (до $50 \mathrm{GPa})$ на электрические и магнитные свойства кристаллических материалов на основе халькогенидов меди и индия с общей формулой $(\operatorname{In} B)_{1-x}\left(\mathrm{Cu} A B_{2}\right)_{x}$ (где $\left.A=\mathrm{As}, \mathrm{Sb} ; B=\mathrm{S}, \mathrm{Se}\right)$, а также кристаллических $\mathrm{CuInSe}_{2}$ и $\mathrm{CuInS}_{2}$.

Исследования выполнены при финансовой поддержке РФФИ (грант № 16-02-00857-a).

DOI: 10.21883/FTT.2017.01.43955.245

\section{1. Введение}

Многокомпонентные кристаллические и аморфные материалы на основе халькогенидов меди, индия и элементов пятой группы $\mathrm{c}$ общей формулой $(A B)_{1-x}\left(C D B_{2}\right)_{x}($ где $A=\mathrm{Ge}, \mathrm{In} ; B=\mathrm{S}, \mathrm{Se} ; C=\mathrm{Ag}, \mathrm{Cu}$; $D=\mathrm{As}, \mathrm{Sb})$ обладают интересными физическими свойствами, проявляя (иногда одновременно) ионную проводимость и высокую фоточувствительность [1-3], сегнетоэлектрические свойства $[1,2]$ и наличие вентильного эффекта [2]. В некоторых материалах этой системы в условиях высоких давлений при комнатной температуре наблюдаются фазовые переходы и отрицательное магнитосопротивление $[4,5]$.

В настоящей работе представлены результаты исследований магнитной восприимчивости (при температурах от 2 до $300 \mathrm{~K}$ ), магнитосопротивления и электрических свойств (в условиях низких температур и давлений до $50 \mathrm{GPa}$ ) материалов, относящихся к указанной выше системе $(\mathrm{InS})_{0.5}\left(\mathrm{CuAsS}_{2}\right)_{0.5}$, $(\mathrm{InSe})_{0.5}\left(\mathrm{CuAsSe}_{2}\right)_{0.5}$ и $(\mathrm{InS})_{0.5}\left(\mathrm{CuSbS}_{2}\right)_{0.5}$, соответствующих формулам CuInAsS $3, \mathrm{CuInAsSe}_{3}$ и $\mathrm{CuInSbS}_{3}$, а также соединений $\mathrm{CuInSe} 2$ и $\mathrm{CuInS}_{2}$.

\section{2. Методика и техника эксперимента}

Соединения $\mathrm{CuInAsS}$, CuInAsSe 3 и $\mathrm{CuInSbS}_{3}$ кристаллизуются в тетрагональной сингонии. На дифрактограммах материалов присутствует серия линий структуры халькопирита. Наблюдается преимущественная ориентация в направлении (112), степень ориентации составляет около 65\% для материалов $\mathrm{CuInAsS}_{3}$ и $\mathrm{CuInSbS}_{3}$. Параметры решеток, близкие к параметрам решеток соединений $\mathrm{CuInSe} 2$ и $\mathrm{CuInS}_{2}$, имеющих структуру халькопирита, меняются с изменением радиусов входящих элементов (см. таблицу). Атомы мышьяка (или сурьмы) могут занимать такие же тетраэдрические позиции, которые занимают атомы меди и индия в структуре $\mathrm{CuInSe} \mathrm{S}_{2}$ и $\mathrm{CuInS}_{2}$, или тетраэдрические пустоты в структуре халькопирита. На возможность этого указывают близкие значения ионных радиусов и заряды соответствующих ионов. При синтезе поликристаллов вырастали крупные моноблоки. При изготовлении образцов слитки хорошо раскалывались вдоль плоскости (112).

Исследования и анализ влияния частоты электрического поля, температуры и давления на электрические и магнитные свойства соединений проведены в области частот $10 \mu \mathrm{Hz}-32 \mathrm{MHz}$, в интервале температур 2-300 K при давлениях до $50 \mathrm{GPa}$. Измерения температурных и барических зависимостей электрических свойств и определение частотных областей, в которых максимально исключены влияния границ образец-электрод, проводились с помощью импедансметра/диэлектрического спектрометра Solartron 1260A и системы ModuLab Materials Test System. Низкотемпературные измерения проводили, помещая образцы в автономный криостат замкнутого цикла с двухступенчатым криогенным рефрижератором DE-204SL. Для генерации высоких давлений применялись камеры высокого давления (КВД) с наковаль-

Параметры элементарных ячеек исследованных соединений, кристаллизующихся в тетрагональной сингонии

\begin{tabular}{l|c|c}
\hline Соединение & Параметры ячейки, nm & $c / a$ \\
\hline $\mathrm{CuInAsSe}_{3}$ & $a=0.57967, c=1.15471$ & 1.9908 \\
$\mathrm{CuInAsS}_{3}$ & $a=0.55184, c=1.10845$ & 2.0086 \\
$\mathrm{CuInSbS}_{3}$ & $a=0.55406, c=1.10750$ & 1.9989 \\
$\mathrm{CuInSe}_{2}$ & $a=0.57820, c=1.16217$ & 2.0099 \\
$\mathrm{CuInS}_{2}$ & $a=0.55227, c=1.11000$ & 2.0098
\end{tabular}


нями из алмазов типа „карбонадо“, которые хорошо проводят электрический ток и служат электродами, позволяя измерять электрические свойства материала непосредственно во время деформации. Градуировка КВД и технические детали подробно описаны в [6]. При измерении магнитосопротивления в поперечном магнитном поле при значениях индукции до 1 Т КВД помещались в панцирный магнит. Установка позволяла независимо изменять величину давления и магнитного поля непосредственно в ходе эксперимента.

Измерения магнитной восприимчивости в интервале температур 2-300 K проводились с помощью SQUID-магнитометра MPMS (Magnetic Property Measurement System)-XL-7 EC. Чувствительность при измерениях магнитного момента при возвратно-поступательном движении образца или при так называемых RSO-измерениях (RSO - reciprocating sample option) составляла $1 \cdot 10^{-8} \mathrm{G} \cdot \mathrm{cm}^{3}$.

\section{3. Результаты и их обсуждение}

Исследованные материалы проявляют активационный тип проводимости. В $\mathrm{CuInAsSe}_{3}$ наблюдалась аномалия диэлектрической проницаемости в интервале 190-220 K [2]. Замена селена на серу в этом соединении привела к появлению ионного переноса, поэтому $\mathrm{CuInAsS}_{3}$, а также $\mathrm{CuInSbS}_{3}$ являются смешанными электронно-ионными проводниками. Доля ионной проводимости составляет $15-20 \%$ от общей проводимости. Область температур начала заметного ионного переноса в $\mathrm{CuInSbS}_{3}(240-270 \mathrm{~K})$ при замене мышьяка на сурьму в соединении $\mathrm{CuInAsS}_{3}$ понизилась на $20-30 \mathrm{~K}$ по сравнению с соответствующей температурной областью в соединении $\mathrm{CuInAsS} 3(260-300 \mathrm{~K})$. На рис. 1 представлены температурные зависимости электрических свойств $\mathrm{CuInSbS}$, пунктирными линиями отмечена температурная область начала заметного ионного переноса.

Исследования магнитной восприимчивости $\mathrm{CuInAsSe}_{3}, \mathrm{CuInAsS}, \mathrm{CuInSbS}_{3}, \mathrm{CuInSe}_{2}, \mathrm{CuInS}_{2}$ в температурном интервале $2-300 \mathrm{~K}$ в области магнитных полей до 7 Т проведены с целью возможной оценки доли ионности связи, установления наличия парамагнитной составляющей магнитной восприимчивости при низких температурах. В соединениях, которые активно исследуются как материалы, перспективные для фотоники, таких как $\mathrm{CuInSe} \mathrm{In}_{2}$ и $\mathrm{CuInS}_{2}$, наличие атомной диффузии и ионного переноса по катионам первой группы может влиять на свойства и определять особенности их поведения при изменении термодинамических условий. Ковалентно-ионная связь (характерная для соединений типа $A^{\mathrm{I}} B^{\mathrm{III}} C_{2}^{\mathrm{VI}}$, а также других соединений на их основе) и соотношение ковалентного и ионного типов связей определяют транспортные свойства, такие как энергия активации электропроводности, наличие и доля ионного переноса, характеристики диэлектрических постоянных и др. Зависимость магнитной восприимчивости со- единений $\mathrm{CuInSe}_{2}, \mathrm{CuInS}_{2}, \mathrm{CuInAsSe}_{3}, \mathrm{CuInAsS}_{3}$ от температуры в области от 75 до $300 \mathrm{~K}$ характерна для диамагнетиков, более сложная зависимость наблюдалась для $\mathrm{CuInSbS}_{3}$ (рис. 2). При понижении температуры от
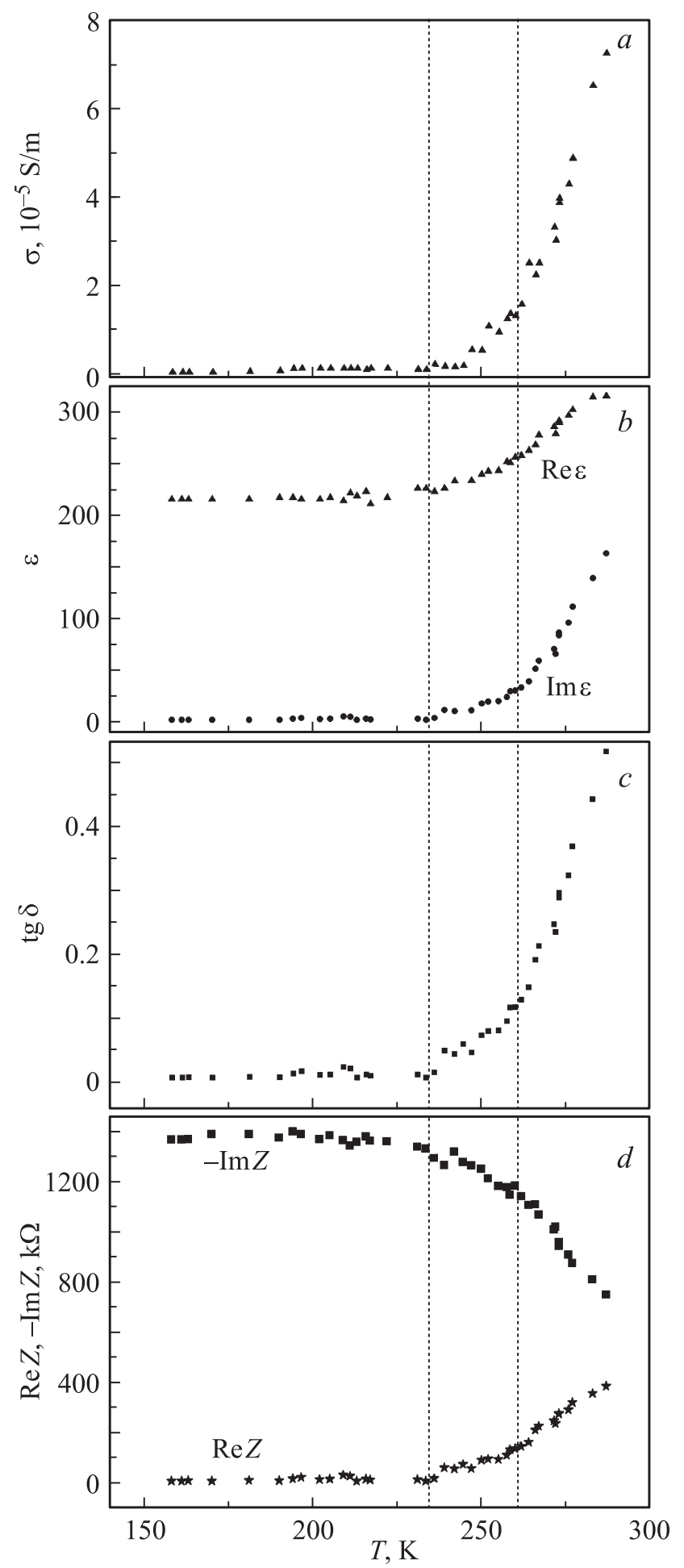

Рис. 1. Температурные зависимости удельной электропроводности $(a)$, диэлектрической проницаемости $(b)$, тангенса угла диэлектрических потерь $(c)$, вещественной и мнимой частей импеданса $(d) \mathrm{CuInSbS}_{3}$. Частота $8 \mathrm{kHz}$, медные электроды. 


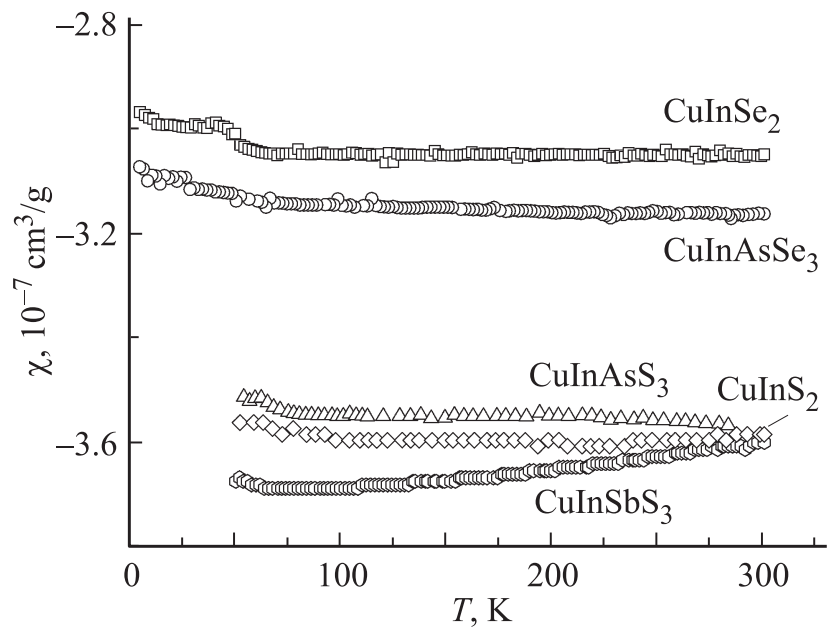

Рис. 2. Температурные зависимости магнитной восприимчивости исследованных соединений в поле $7 \mathrm{~T}$.

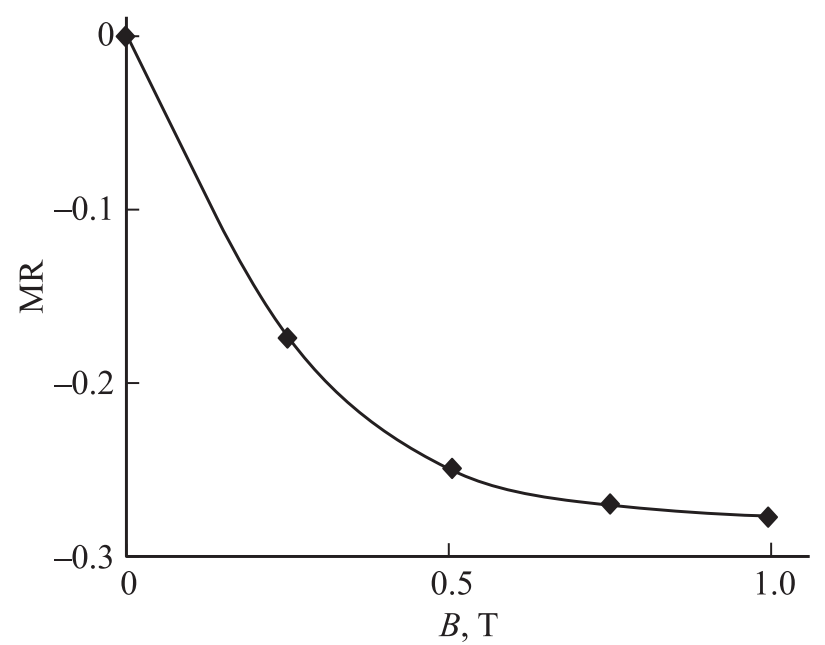

Рис. 3. Полевая зависимость магнитосопротивления CuInAsSe 3 при давлении $20 \mathrm{GPa}(T=300 \mathrm{~K})$.

75 до $2 \mathrm{~K}$ магнитная восприимчивость уменьшается по модулю, что можно связать с ростом ее парамагнитной составляющей. Наблюдаемые значения парамагнитной восприимчивости могут быть объяснены наличием ионов $\mathrm{Cu}^{2+}$, содержащих нечетное число электронов. Аналогичная ситуация наблюдалась при исследовании соединения $\mathrm{Cu}_{3} \mathrm{SbS}_{3}$ [7], когда наличие связей $\mathrm{Cu}-\mathrm{S}-\mathrm{Cu}$ и ионов $\mathrm{Cu}^{2+}$ при уменьшении температуры обусловливало переход от диамагнитного состояния в парамагнитное, вызванное собственными магнитными моментами неспаренных электронов в ионах $\mathrm{Cu}^{2+}$. Оценены ланжевеновская магнитная восприимчивость ионных остовов атомов решетки (по формуле Кирквуда [8]) и парамагнитная составляющая при низких температурах в материалах. Проведена оценка количества парамагнитных центров при условии, что кюри-вейссовский парамагнетизм вызван собственными магнитными моментами неспаренных электронов в ионах $\mathrm{Cu}^{2+}$, содержащих нечетное число электронов. По оценкам, проведенным для соединения $\mathrm{CuInSbS}_{3}$, значения ланжевеновской и ван-флековской составляющих магнитной восприимчивости равны $-0.568 \cdot 10^{-6}$ и $0.198 \cdot 10^{-6} \mathrm{~cm}^{3} / \mathrm{g}$ соответственно. Аналогичные оценки для $\mathrm{CuInS}_{2}$ позволили установить значение удельной восприимчивости Ланжевена $\left(-0.526 \cdot 10^{-6} \mathrm{~cm}^{3} / \mathrm{g}\right)$, а также ван-флековской парамагнитной восприимчивости, обусловленной отклонением распределения электронной плотности атомов от сферической симметрии $\left(0.166 \cdot 10^{-6} \mathrm{~cm}^{3} / \mathrm{g}\right)$, и если кюри-вейссовский парамагнетизм вызван ионами $\mathrm{Cu}^{2+}$, то такие ионы содержатся приблизительно в одной молекуле из 140.

Анализ влияния высоких статических давлений (до $50 \mathrm{GPa}$ ) на электросопротивление $R$ и магнитосопротивление MR изучаемых материалов позволил определить барические области, в которых наблюдаются существенные изменения в поведении электрических характеристик и MR материалов. Установлено, что для $\mathrm{CuInAsS}_{3}$ и $\mathrm{CuInAsSe}_{3} \mathrm{MR}<0$ в области давлений 15-50 GPa. Полевая зависимость MR для $\mathrm{CuInAsSe}_{3}$ при давлении $P=20 \mathrm{GPa}$ представлена на рис. 3. Существует корреляция между особенностями поведения электро- и магнитосопротивления при изменении давления. На кривых $R(P)$ и $\mathrm{MR}(P)$ одновременно наблюдались экстремумы в барических областях 17-19, 28-32, $36-38 \mathrm{GPa}$ для $\mathrm{CuInSbS}_{3}, 38-40 \mathrm{GPa}$ для $\mathrm{CuInAsS}_{3}$ и 36-38 GPa для CuInAsSe 3 . Наблюдаемые сдвиги интервалов возможных структурных переходов в области давлений $36-40 \mathrm{GPa}$ при изменении радиусов атомов элементов, входящих в соединения, могут быть объяснены эффектом химического сжатия решетки. Полученные области давлений близки к барическим интервалам, в которых существенно менялось поведение параметров, характеризующих импеданс материалов, и согласуются с ранее проведенными для некоторых из них оценками [4]. Аналогичные особенности электрических характеристик при увеличении давления до $50 \mathrm{GPa}$, такие как проявление отрицательного MR, смена знака термоэдс, аномалии на барических зависимостях параметров импеданса и времен релаксации электросопротивления, наблюдались и в поликристаллических $\mathrm{CuInSe}_{2}$ и $\mathrm{CuInS}_{2}$. В работе [5] отмечалось, что наблюдаемое поведение свойств при указанных давлениях согласуется с данными о барических структурных переходах в $\mathrm{CuInSe}_{2}$ и $\mathrm{CuInS}_{2}$. Указанные особенности поведения свойств соединений $\mathrm{CuInSbS}_{3}, \mathrm{CuInAsS}_{3}, \mathrm{CuInAsSe}_{3}$ при увеличении давления также могут быть связаны с барическими структурными изменениями кристаллической решетки и изменением электронной структуры.

\section{4. Заключение}

Исследовано влияние температур 2-300 K и высоких давлений до $50 \mathrm{GPa}$ на электрические и магнитные свойства кристаллических материалов на основе халько- 
генидов меди и индия: CuInAsSe $3, \mathrm{CuInSbS}_{3}, \mathrm{CuInAsS}_{3}$, $\mathrm{CuInSe}_{2}$ и $\mathrm{CuInS}_{2}$. Проведены оценки ланжевеновской магнитной восприимчивости ионных остовов атомов решетки и парамагнитной составляющей при низких температурах в материалах. Определены барические области, в которых наблюдаются существенные изменения в поведении электрических характеристик и магнитосопротивления материалов.

\section{Список литературы}

[1] Л.А. Сайпулаева, Ф.С. Габибов, Н.В. Мельникова, А.Г. Алибеков, О.Л. Хейфец, А.Н. Бабушкин, К.В. Курочка. ЖЭТФ 142, 5 (11), 1044 (2012).

[2] Ф.С. Габибов, Е.М. Зобов, Л.А. Сайпулаева, А.Г. Алибеков, Н.В. Мельникова, О.Л. Хейфец. ФТТ 57, 6, 1192 (2015).

[3] N.V. Melnikova, A.Yu. Mollaev, O.L. Kheifets, L.A. Saypulaeva, P.P. Hohlachev, A.G. Alibekov, A.L. Filippov, A.N. Babushkin, K.V. Kurochka. Azerb. J. Phys. 21, 2, 3 (2015).

[4] Н.В. Мельникова, Л.А. Сайпулаева, П.П. Хохлачев, А.Ю. Моллаев, А.Г. Алибеков, К.В. Курочка, О.Л. Хейфец, А.Н. Бабушкин. ФТТ 57, 10, 2025 (2015).

[5] Н.В. Мельникова, А.В. Тебеньков, Г.В. Суханова, И.С. Устинова, А.Н. Бабушкин. Изв. РАН. Сер. физ. 78, 4, 447 (2014).

[6] A.N. Babushkin. High Pres. Res. 6, 349 (1992).

[7] А.Н. Бабушкин. Автореф. докт. дис. УПИ им. С.М. Кирова. Екатеринбург (1992). 39 с.

[8] Ya.G. Dorfman. Diamagnetism and the chemical bond. American Elsevier Publ. (1965). 182 p. 